\title{
Aesthetics in Context-The Role of Aesthetics and Usage Mode for a Website's Success
}

\author{
Glena H. Iten*, Antonin Troendle and Klaus Opwis \\ Department of Psychology, Center for Cognitive Psychology and Methodology, University of Basel, \\ Missionsstrasse 62a, 4055 Basel, Switzerland \\ *Corresponding author: glena.iten@unibas.ch
}

\begin{abstract}
A widespread belief attributes the first impression to be decisive for retaining users on websites. However, empirical investigation on this conjecture has been largely omitted. This paper examines the influence of positive and negative first impressions on subsequent website usage decisions in three different user tasks. In all tasks appealing or non-appealing website screenshots were displayed. In the first two tasks, websites were shortly presented, examining the willingness to view and the intention to stay on websites. In the third task, participants were able to browse naturally, scanning websites, deciding whether to use the website or not, and taking action eventually. Additionally, the $N=120$ participants either were given or not given an explicit goal to solve in each task. Data was analysed with different statistical methods (ANOVA, McNemar and Survival Analysis). While the first impression's significance was demonstrated in Tasks 1 and 2 for both goal mode and action mode, the usage mode was decisive for retaining users on websites in the most realistic user scenario in Task 3. Overall the effect sizes indicated that the significant differences were substantial, ranging from medium to large (Task 1: $\eta_{\mathrm{p}}{ }^{2}=0.35 / 0.66$; Task 2 : $\mathrm{OR}=$ 3.25/5.81; Task 3: OR=2.11).
\end{abstract}

\section{RESEARCH HIGHLIGHTS}

- This experimental study investigates the widespread belief that the first impression is decisive for retaining users on website.

- An appealing first impression impacts subsequent usage behaviour only under certain circumstances.

- After a short exposure to an appealing website, participants decided to view it or stay on it regardless of their usage mode (goal and action mode).

- When observing more realistic website exploration behaviour, the impact of first impression vanishes.

- Being able to explore a website self-paced, participants in goal mode persevere longer on it regardless of their first impression of the website.

Keywords: 1.1.1.6 laboratory experiments; 1.1.4 HCI theory, concept and models; 1.1 .7 empirical studies in HCI; 1.2.1.1 user interface design

Editorial Board Member: Dr. Javier Bargas-Avila

Received 29 August 2017; Revised 5 January 2018; Editorial Decision 8 January 2018; Accepted 17 January 2018

\section{INTRODUCTION}

The World Wide Web counts over 1 billion active websites. Google provides you with more than 4 Million search results when looking for 'chocolate cake recipe'. To come out on top against this plethora of websites, a positive first impression is considered of advantage. Internet users draw inferences based on outer appearance to other website characteristics, making aesthetic a key factor in website interfaces (van Schaik et al., 2012). Since the aesthetic processing occurs instantly (Leder et al., 2004; Thielsch and Hirschfeld, 2010), the first 
impression is considered a vital factor for website success (Lindgaard et al., 2011).

Within psychological domains involving human interaction it is widely accepted that the first impression is crucial in regard to how people perceive, judge and, consequently, act (Lindgaard et al., 2011; Olivola and Todorov, 2010). Within the field of human-computer interaction (HCI) the topic gained centre stage when Lindgaard et al. (2006) made a highly important discovery with their study, showing that an exposure time of $50 \mathrm{~ms}$ is sufficient for reliable and consistent appraisals of website aesthetics. Those findings evoked comprehensive research on aesthetics in the context of users' first impression, bringing together further evidence on the immediacy of aesthetic appraisals (Harrison et al., 2015; Tractinsky et al., 2006) as well as specific features contributing to its formation (Tuch et al., 2012b).

In the course of this research movement, a general acceptance emerged that accredits to the first impression of being the decisive factor for capturing users' interest and, on top of that, determining the users' subsequent behaviour in terms of whether they stay on or leave websites (Douneva et al., 2016; Geissler et al., 2006; Lindgaard et al., 2011; Robins and Holmes, 2008; Tuch et al., 2012b; van Schaik and Ling, 2009). Indeed, in reference to the aesthetics' wide-ranging impact (van Schaik et al., 2012) and considering the close relationship between aesthetics and first impression (Lindgaard et al., 2011), the assumed influence of first impressions on users' subsequent behaviour stands to reason. However, this prevalent opinion is an assumption that has yet not been empirically tested.

In this study we address the effect of first impressions in regard to its actual impact on users' subsequent website usage behaviour. We aim to contribute to the clarification of this issue by setting up three complementary controlled tasks in a laboratory experiment. To this end, we manipulated interface aesthetics in order to evoke positive and negative first impressions. The study proceeds in an information search context including two different mindsets (i.e. usage mode). For a better understanding from where the often-claimed impact of first impressions originates, the following section will first briefly attend the role of aesthetics in different psychological domains. Then, the interplay of aesthetics and first impression will be reviewed. Finally, the context of use will be introduced.

\section{THEORETICAL BACKGROUND}

A great body of research from different psychological domains illustrates the power of attractiveness, aesthetics, beauty or visual appeal. In HCI, research has highlighted the positive impact of website aesthetics on constructs such as overall impression (Thielsch et al., 2013; van Schaik et al., 2012), website utility (Jiang et al., 2016), trust and credibility (Lindgaard et al., 2011; Robins and Holmes, 2008), perceived information quality (De Angeli et al., 2006; Hartmann et al.,
2008), and, conceivably, perceived usability (Sonderegger and Sauer, 2010; Tractinsky et al., 2000; Tuch et al., 2012a) for several years by now. The psychological mechanism behind that deductive reasoning of visual cues to other characteristics is often referred to by the 'halo effect' (Moshagen and Thielsch, 2013). Thus, perceived aesthetics may affect people's attitude towards a website and its inherent qualities, meaning that users tend to tolerate certain product shortcomings following a positive first impression.

\subsection{The interplay of aesthetics and first impression}

In previous years, aesthetics has been established as a multidimensional construct in HCI, labeled with diverging definitions (Lavie and Tractinsky, 2004; Moshagen and Thielsch, 2010). In this paper the definition of Moshagen and Thielsch (2010) is adopted, which is read as 'an immediate pleasurable subjective experience that is directed towards an object' (p. 3). As appears from this definition, the aesthetic processing occurs instantaneous and thus makes the first impression valuable. The relation between aesthetics and first impression is also empirically underpinned since aesthetics was shown to be highly relevant in the development of first impressions (Thielsch and Hirschfeld, 2010). It was further demonstrated that aesthetics has clearly the greatest impact on websites' first impression in comparison to content and usability (Flacke et al., 2015; Thielsch et al., 2013) or credibility and usability (Kim and Fesenmaier, 2008; Lindgaard et al., 2011). The aesthetics' influence on the first impression is evident and hence, a deeper understanding of the underlying factors contributing to the formation of first impressions had been of interest. As a result, various studies on first impression with regard to aesthetics identified critical properties of websites, which affect the initial impression. Thereby, colours (Reinecke et al., 2013), visual complexity (Michailidou et al., 2008; Reinecke et al., 2013; Tuch et al., 2012b) and prototypicality (Tuch et al., 2012b) were shown to be most influential.

For all that, defining the first impression's time frame proves difficult. Indeed, research within HCI demonstrated that $500 \mathrm{~ms}$ or even below suffice to form reliable preferences towards websites (Lindgaard et al., 2006; Tractinsky et al., 2006). While these studies present evidence based on laboratory experiments with varying stimuli presentation times (e.g. presentation for 50-500 ms), recent studies looking at physiological data found different neural activation at $100 \mathrm{~ms}$ for aesthetically pleasant versus unpleasant interfaces after stimuli onset (Bölte et al., 2017; Ding et al., 2017), supporting that aesthetic processing occurs very early. Moreover, these initial decisions are manifested of being stable over time (e.g. ratings after $500 \mathrm{~ms}$ correlated highly with those after $10 \mathrm{~s}$, Tractinsky et al., 2006). This is commonly attributed to the confirmation bias, which depicts the mannerism to look for 
confirming evidence supporting the initial impression and ignoring conflicting information (Nickerson, 1998).

Not only is it tricky to put a number on the first impression's time frame, the time span of the first impression's ability to affect users' actions is somewhat elusive as well. Some authors separate the first impression into immediate and deliberate first impressions (Douneva et al., 2016; Thielsch and Hirschfeld, 2012; van Schaik and Ling, 2009). Immediate refers to a bottom-up process of the visual perception, and deliberate corresponds to a top-down processing, whereby reflective cognitive processes and reasoning occur. Thielsch and Hirschfeld (2012) suggest that deliberate judgments are not feasible within $50 \mathrm{~ms}$ but may start around $500 \mathrm{~ms}$ as these judgments correlate highly with judgments after $10 \mathrm{~s}$. Their conception complies with Zajonc (1980), saying that judgments below $50 \mathrm{~ms}$ are due to affective responses, starting even before cognitive processing happens. Still, both phases are interrelated; the deliberate first impression is built on the immediate affective response and only performs slight modifications upon it (van Schaik and Ling, 2009). This seems to be relevant when considering that staying on and leaving a website are deliberate decisions.

As just indicated, the field of interest of the present study concerns the deliberate website usage behaviour in dependence of positive and negative first impressions. That is, whether participants will stay on or leave a given website. Studies on that subject matter are virtually absent. Yet, little research with regard to the general impact of aesthetics on users' subsequent behaviour is reported. However, the subsequent behaviour has been understood in many ways such as buying intentions (Hall and Hanna, 2004; Parboteeah et al., 2009), intention to revisit (Thielsch et al., 2013), or task performance (Sonderegger and Sauer, 2010; Sonderegger et al., 2012). In respect of the relationship between aesthetics and usage behaviour towards websites (i.e. staying or leaving a website), only one study yields a subtle hint that users occasionally dismiss websites as a result of non-appealing design (Sillence et al., 2007). Another study on learning American Sign Language found that dwell time was higher when students learned with an appealing than with a non-appealing website (Miller, 2011).

A successful website is characterized best by its actual use. Users' dwell time on a page can act as an indicator for its success. In a large-scale log analysis Liu et al. (2010) made a remarkable effort, investigating the dwell time of 205873 different websites with 10000 visits per page at least. Their findings support the notion of the first impression's importance in general but are also indicative of a longer sphere of action than the $50 \mathrm{~ms}$ range suggested by Lindgaard et al. (2006). According to their data, websites experience a strong negative aging effect, which basically consists of two phases. First, websites undergo an initial screening, resulting in a substantial probability of leaving the pages. Second, in case the screening is overcome, the likelihood of leaving reaches a plateau, that means, the leaving rate decreases gradually. More precisely, their findings suggest that the first $10 \mathrm{~s}$ are pivotal for a website's success in terms of persuading users to use a website.

However, to our knowledge, no study has experimentally investigated the effects of first impressions on the subsequent website usage behaviour. Hence, the current study strives to shed light on how users' time spent on websites is affected by antecedent first impressions.

\subsection{Usage mode}

The first impression's subsequent behaviour response is hardly straightforward since, apart from design characteristics, it depends on several other factors including contextual factors such as usage mode or website genre (Lindgaard et al. 2011). Naturally, the website's genre and its content provide the framework for website usage. Among those, searching for information has classed a top position in daily internet activities (Wellman and Haythornthwaite, 2008).

Yet, just like the presence of a hammer alone does not cause people to use it, website usage inevitably depends on some sort of behaviour intention. This leads up to the usage mode. Hassenzahl (2003) strongly emphasized that website usage always includes a particular mode. The underlying concept refers to two different mindsets, called goal and action mode. In goal mode, users focus on a specific objective that motivates all actions and the system embodies no more than 'a means to an end'. Thus, users strive to accomplish a task efficiently without getting sidetracked by focusing their attention and hence mental effort on fulfilling a certain goal (Hassenzahl and Ullrich, 2007). The concentration of the attentional resources on a specific goal characterized the underlying cognitive processes behind goal mode. In action mode, the software represents 'an end in itself' and may refer to what is colloquially known as 'surfing the web' (i.e. exploring) (Hassenzahl, 2003). Hence, users are in an exploratory mode and their perception might be more sensitive to aesthetics, as it is assumed that users in action mode allocate their attentional resources or mental effort on different features simultaneously (Hassenzahl and Ullrich, 2007). Thus, aesthetics might affect their behaviour in greater extent.

The possible significance of context regarding the perception of aesthetics (De Angeli et al., 2006), performance (Sonderegger and Sauer, 2010), or online information search behaviour (Kim and Fesenmaier, 2008), has been mentioned occasionally. Thereupon, several researchers integrated the usage mode by inducing participants into either task-oriented (i.e. goal mode) or explorative (i.e. action mode) usage modes (Kauer et al., 2013; Van Schaik and Ling, 2009; Van Schaik and Ling, 2011). This manipulation is achieved by providing participants with a context (e.g. visiting a specific website) and either charging them with a specific task such as information retrieval (goal mode) or simply letting them explore the 
given website in their own interest (action mode). The findings of the aforementioned researchers imply that perceptual judgments (e.g. on the website's visual appeal) depend to some extent on the usage mode (Hassenzahl, 2003; Van Schaik and Ling, 2009).

For users with an explicit goal in mind, perceived website aesthetics relies on what Hassenzahl calls hedonic (e.g. aesthetics) and pragmatic qualities (i.e. usability), whereas in action mode only hedonic quality counts as an influential variable for perceived appeal. The consequences arising thereby can be of behavioural nature such as spending more time on a website (Hassenzahl, 2003). To summarize, users in action mode ('playful and spontaneous') are guided by stimulation and aesthetics, whereas users in goal mode ('serious' and 'planning') do not let themselves be solely carried away by hedonic qualities but rather appreciate pragmatic features beyond the hedonic (Hassenzahl et al., 2002; Van Schaik and Ling, 2011).

Although the relationship between aesthetic perception and usage mode has been highlighted, the usage mode has not been taken into account by previous research in connection with first impressions (cf. Lindgaard et al., 2006; Tractinsky et al., 2006; Tuch et al., 2012b). Thus, the current paper aims to expand this course of research by inducing participant into a particular usage mode.

\subsection{Aim of the study}

The present research has one prime objective, namely to validate experimentally the often implied impact of the first impression on the subsequent usage behaviour. For this purpose, three complementary tasks were designed.

The first task has the aim to analyse the first impression's impact on participants' willingness to view a given website. We expect that positive first impressions increase the willingness to view websites compared with negative first impressions $\left(H_{1}\right)$. Based on Hassenzahl (2003), suggesting that users in goal mode are focused on accomplishing their goal and hence may care less about visual aesthetics. Conversely, users within action mode may be swayed by hedonic (i.e. aesthetic) aspects to a greater extent. Consequently, we expect further that negative first impressions lead to lesser willingness to view websites in action mode than in goal mode $\left(H_{2}\right)$.

Task 2 pursues a similar target as the previous albeit with a modified procedure. We anticipate a difference between the intentions to stay on websites following either positive or negative first impressions $\left(H_{3}\right)$.

The goal of the third task is twofold. First, we believe that negative first impressions cause faster website abandonment than positive first impressions $\left(H_{4}\right)$. We further assume that the effect of $H_{4}$ is more pronounced in action mode than in goal mode $\left(H_{5}\right)$, since in action mode aesthetics is of higher importance (Hassenzahl, 2003). Second, we want to decode the critical phases that determine whether a website is used or not.

\subsection{Methodological approach}

Assessing usage behaviour on websites by means of questionnaires is a common (cf. Hall and Hanna, 2004; Parboteeah et al., 2009; Thielsch et al., 2013) but perhaps limited approach, because self-reported behaviour may not correspond with actual behaviour. To address this gap, this study is modeled in order to retrieve participants' behaviour directly by gathering their actions during certain tasks. Therefore, this experiment consists of three consecutive usage tasks, which were conducted in the context of three different information search scenarios. Apart from the topic's relevance, the information search genre appears suitable to address and control, respectively, the constructs of aesthetics, content, and usability, which were previously found to contribute to first and overall impressions of websites (Thielsch et al., 2013). However, as mentioned at the beginning, aesthetics was shown to make the major contribution to the first impression of websites (Lindgaard et al., 2011). Therefore, the manipulation of the first impression was performed by varying the website's aesthetics (i.e. appealing and non-appealing, respectively). These websites were tested in a preliminary study that is reported in the section hereafter. In order to reduce confounding factors, content was held constant (Tasks 1 and 2) or counterbalanced (Task 3). As the information websites are confined to scrolling up and down, we further believe that usability has no or very weak interfering effects. The usage mode was implemented for providing a context in which the participants act, as online activities include either a goal or action mode (Hassenzahl, 2003). The instructions concerning usage mode were realized based on van Schaik and Ling's (2009) approach.

Note that positive first impressions correspond to appealing websites and negative first impressions correspond to nonappealing websites throughout this study.

\section{METHODS}

\subsection{Preliminary study}

To ensure that participants truly experience a first impression we developed 28 website layouts and validated them in an online study in regard to their visual appeal. To reduce workload, the 94 participants $\left(M_{\text {age }}=24.2, S D_{\text {age }}=14.8 ; 64\right.$ women, 28 men, 2 other) were presented with 15 randomly assigned website screenshots each. All websites contained the same filler text ('lorem ipsum') and the same placeholder image. The websites only varied in structure, colour (text and background) and font. The screenshots were displayed for $2 \mathrm{~s}$. We used a 2-s exposure because we reckoned with loading delays due to the relatively large size of the screenshots. All websites were rated between 43 and 56 times on 7-point Likert scale regarding their visual appeal by use of a validated questionnaire (i.e. VisAWI-Short, Moshagen and Thielsch, 


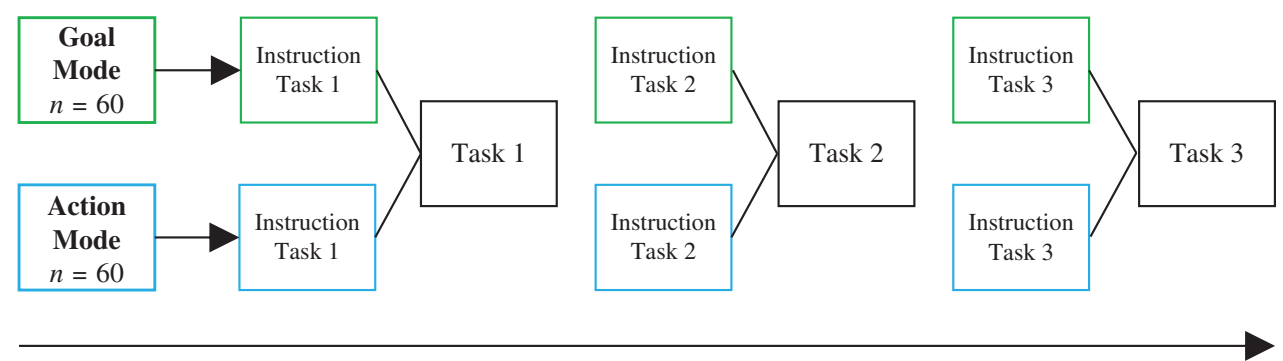

FIGURE 1. Overall procedure of the laboratory experiment. The user tasks asked participants to visit several websites to get information on three different topics. In Tasks 1 and 2 several websites were presented for $2 \mathrm{~s}$, whereas in Task 3 participants had 1 minute to investigate $1-6$ websites self-paced.

2013). The seven best-rated $(M=4.65 ; S D=0.84$, Range: 4.57-4.84) and the seven worst-rated $(M=2.67 ; S D=0.94$. Range: $2.14-2.88$ ) websites were applied as stimuli material for the three tasks of the main study (Cohen's $d=2.22$ ). Therefore, the filler text as well as the placeholder image was replaced with a content and image relating to the respective tasks' topic. The remaining 14 website, that were excluded for the main study, ranged from 3.29 to 4.53 with an average of $M=4.10$ and $S D=1.28$.

\subsection{Laboratory experiment}

The experiment aimed at establishing clarity regarding postfirst impressions behaviour in terms of users' willingness to view, intention to stay and actual usage of a given website. For an overview of the whole experiment, see Fig. 1.

\subsubsection{Design}

This experiment used a two-way, mixed design with the within-subject independent variable website aesthetics (appealing, non-appealing) and the between-subject independent variable usage mode (goal, action). The goal condition consisted of a specific task (i.e. finding an answer). The action condition included no specific task (i.e. exploring). The dependent variables were either the willingness to view a given website (Task 1), the intention to stay on a website (Task 2), and the dwell time on the first visited webpage (Task 3). Figure 1 depicts the overall procedure and design of the experiment.

\subsubsection{Participants}

Participants were recruited through the recruiting database of the Department of Psychology of the authors' university. In this database, students can sign up for studies in exchange for course credits or they received an equivalent of US\$ 5 instead. Overall, there were $N=120$ participants (90 females) with a mean age of 22.9 years $(S D=3.8)$ and an age range of $18-36$.

\subsubsection{Materials}

The experiment was implemented with the survey tool Unipark EFS survey and conducted on iMacs (Mac OS X 10.8.5) using 21.5 in. monitors with a resolution of $1920 \times$ 1080 pixels.

\subsubsection{Experimental setup}

The experiment was conducted in the computer lab of our Department. Participants took part alone or in groups of up to 10 people who worked independently. They were allocated in front of an iMac with at least one empty seat in between every participant. Thereafter, the experimenter informed them that a connection error with the Internet occurs occasionally. ${ }^{1}$ Further, they were told that in such a case, insofar as possible, they should follow the instruction on the computer screen. All other instructions were displayed on the screen. They were able to control the progress of the experiment by clicking the continue button. The survey software assigned the participants randomly to one of the two experimental between-subject conditions (i.e. goal or action mode). After a welcoming screen, participants were briefed about the procedure of each task. Participants were then instructed to perform three tasks demanding a search of information on three different topics. After the completion of all three tasks, as a manipulation check for user mode, participants were asked to indicate whether they were instructed with a specific task (e.g. answer questions), or whether they had no specific task (e.g. freely explore), or whether none of those two options applied. In the end they had to provide some demographical data, were thanked and received their compensation.

\section{TASK 1}

\subsection{Procedure}

Participants were asked to project their thoughts into the following scenario: 'you fell down on the street sustaining a

\footnotetext{
${ }^{1}$ This information was of importance in regard to Task 2 and is explained in the corresponding section.
} 
sore knee. You are unsure whether a bandage or air (i.e. no bandage) is better for the wound's healing.' Participants allocated to the goal condition were given the following add-on: 'Needless to say, you want that wound to be healed as quickly as possible. For that reason, do an internet search for the right answer.' Then, eight screenshots were presented to all participants in a random order for $2 \mathrm{~s}$ each. This exposure time was used due to the same reasons as described in the preliminary study. Four appealing and four non-appealing screenshots of information websites were used (see Fig. 2). Following every screenshot, participants were asked to indicate whether they want to save that website for later use. At the outset they were informed that from all the websites they save, one would be drawn by chance after making the decisions for the eight websites. In the case where they would not keep any website, one website would be available in a 'random pool' already. Once all decisions were made, all participants were seeing the same website that was not shown beforehand. In the prestudy this website received neither a

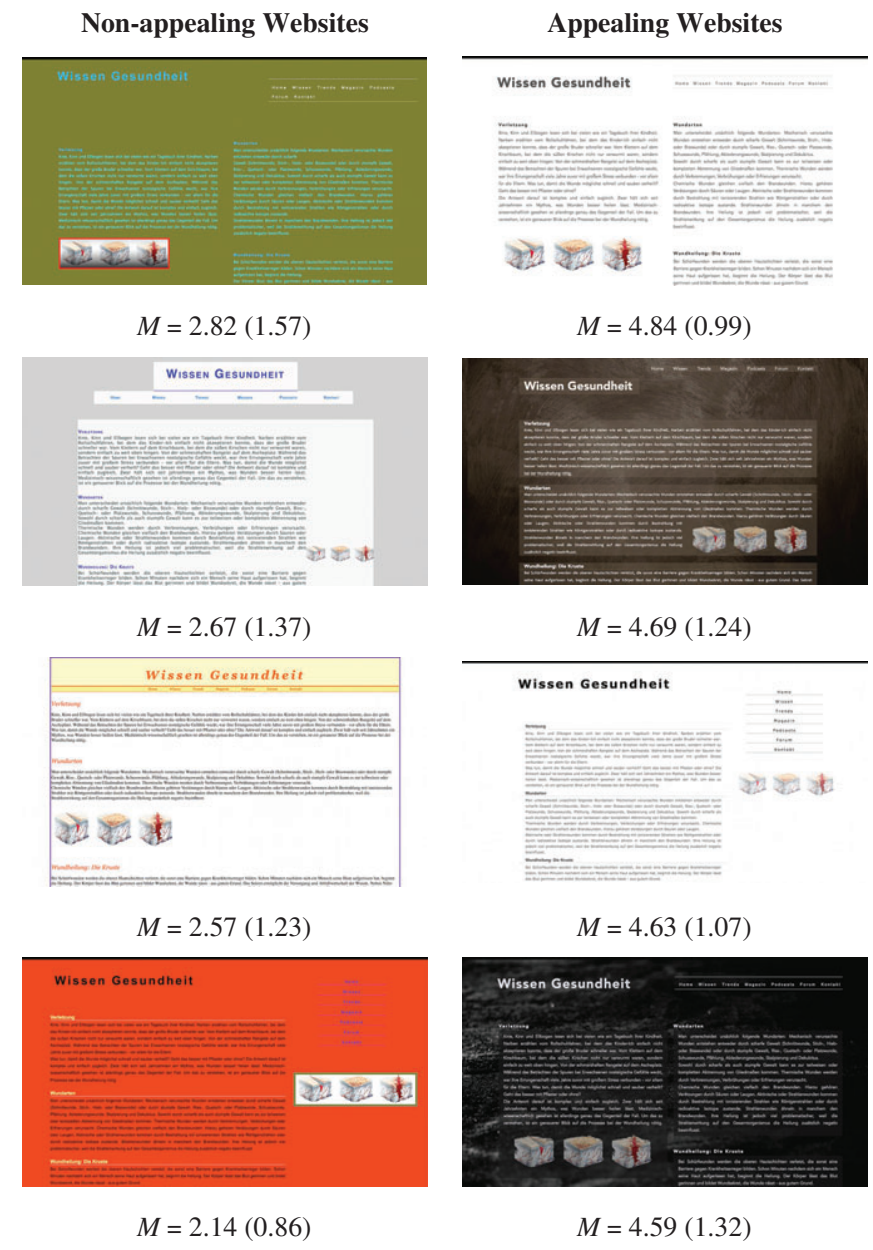

FIGURE 2. Screenshot of Task 1, including the mean and standard deviation of VisAWI ratings (data of the prestudy) under each screenshot. high nor low rating in visual appeal $(M=3.69, S D=1.28$, see Appendix). This website was presented to allow participants to finish the task under the same conditions and was not part of the measurement process in Task 1. However, participants were not aware of it not being a measurement. If participants would have been presented with one of their selections, it would have resulted in a variety of websites presented in the end of Task 1. We selected this neutral website to avoid possible sequence effects of appealing versus non-appealing websites for the next task (Task 2). The only difference between goal and action mode, was that participants in the goal mode condition were requested to answer the question in note form. Finally, participants were instructed that the first part of the experiment is completed and that they may start with the second part when ready.

\subsection{Measures}

After seeing each website participants in goal mode were asked: 'would you like to save this website in order to use it for answering the question afterwards?' Participants in action mode were asked: 'would you like to save this website in order to explore it at your own pace afterwards?' The number of appealing and non-appealing websites participants indicated to save for later use (i.e. willingness to view) was counted. The number of websites each participant was willing to view could range from 0 to 4 for both versions (appealing and non-appealing).

\subsection{Results}

The average numbers of appealing and non-appealing websites participants were willing to view in both usage modes are shown in Fig. 3. A two-way mixed analysis of variance (ANOVA) was applied with website aesthetics as within-subject independent variable and usage mode as between-subject independent variable. The amount of websites participants were willing to view was analysed as the dependent variable. For all statistical tests an alpha level of 0.05 was used and all data were checked to ensure that they met the requirements for the statistical tests.

There was a significant two-way interaction between website aesthetics and usage mode, $F(1,118)=4.41, P=0.038$, partial $\eta^{2}=0.036$. This indicates that for appealing as well as non-appealing websites the willingness to view differs in dependence of the usage mode. Due to a significant interaction, the interpretation of main effects may be misleading (Girden, 1992); therefore, data were analysed post hoc on simple effects using the Bonferroni correction. The simple effect comparing goal and action mode did not reach a statistically significant difference either in appealing $(F(1,118)=$ $0.91, P=0.342)$ nor in non-appealing $(F(1,118)=3.10$, $P=0.081)$ websites. 


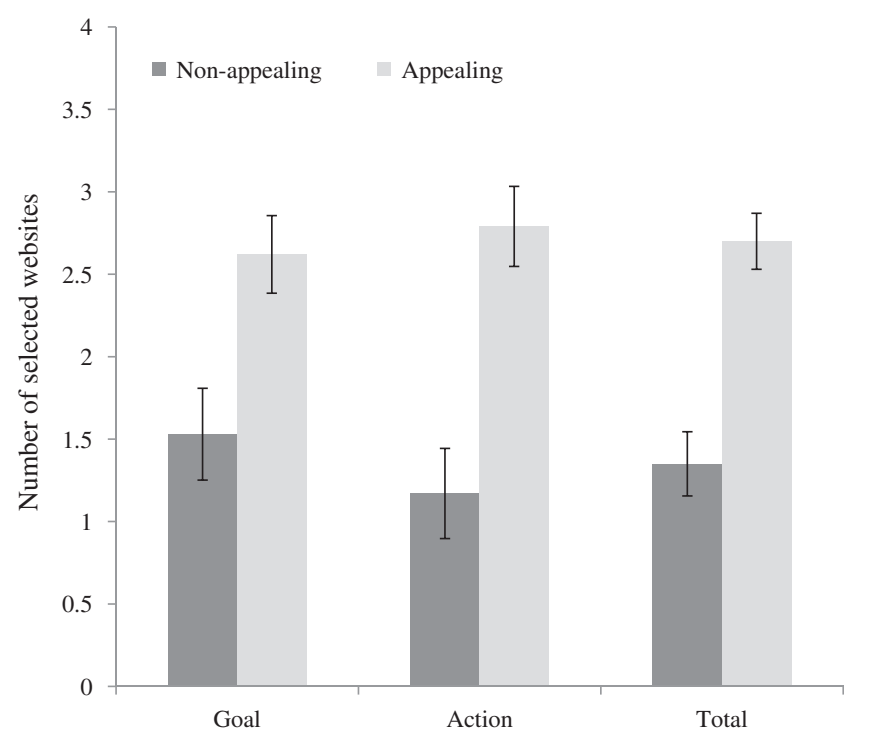

FIGURE 3. Number of selected websites (in percent) participants were willing to view by website esthetics (i.e. first impression) and by mode of use. Error bars are $95 \%$ confidence intervals.

Simple effect analysis revealed a statistically significant effect of website aesthetics on the willingness to view a website within goal mode $(F(1,59)=32.25, P<0.001$, partial $\left.\eta^{2}=0.353\right)$ as well as within action mode $(F(1,59)=$ 111.92, $P<0.001$, partial $\left.\eta^{2}=0.655\right)$. In goal mode, the willingness to view appealing websites was significantly greater than for non-appealing websites $(M=1.096, S E=$ $0.193, P<0.001)$. The same held true for action mode $(M=$ 1.612, $S E=0.152, P<0.001)$.

\subsection{Discussion}

The results of this task are clearly indicative of the first impression's effect on planned website usage. Supporting $H_{1}$, positive first impressions (i.e. appealing websites) caused increased willingness to view websites in comparisons to negative first impressions (i.e. non-appealing websites). Contrary to what was expected in $\mathrm{H}_{2}$, negative first impression did not cause lesser willingness to view websites within action mode compared to goal mode. Nonetheless, as indicated by the significant interaction effect, the first impression's impact differs in dependence of the usage mode. Accordingly, the first impression carries more weight in absence of explicit goals, suggesting that negative first impressions could be all the more impactful for individuals who are just browsing through the Internet (i.e. in action mode). This implies that individuals are more likely to dismiss a website due to a negative first impression. However, in consideration of the interaction's small effect size $\left(\eta_{p}^{2}=0.04\right)$ and non-significant simple effects, this assumption must be treated with care and needs further investigation (see Fig. 3).

The reached decisions (i.e. willingness to view a given website) are attributable to website appeal for the most part. This conclusion is based on the context that other factors (i.e. usability and content, which were previously stressed contributing to first impressions besides aesthetics, Thielsch et al., 2013) presumably only scratched the surface of the participants' perceptions due to the short exposure. This notion achieves support from Robins and Holmes (2008) showed that despite equal content, more appealing websites received increased credibility ratings within roughly $3 \mathrm{~s}$. They argue that during that short time grasping the content's value seems unlikely. Although we equipped our websites with unvarying content in order to reduce the content's potential confounding influence on the perception of aesthetics (cf. Thielsch et al., 2013), it reveals likewise a conceptual limitation of the first part of the experiment. Despite the short exposure time, a few participants (equal number in both modes) noted in an optional comment field that they observed the invariability of the content over all presented websites. However, there is no reason to believe that this shortcoming influences the results systematically either for appealing or non-appealing websites. The large effect sizes $\left(\eta_{p}^{2}\right.$ goal mode $=0.35 ; \eta_{p}^{2}$ action mode $=$ 0.66 ) back up the notion that the existing effect was a consequence of the manipulation of the websites' appeal.

The first task was geared to overcome simple yes-no questions in regard to the willingness to view a website. We provided a context in which we were able to assess the participants' actual behaviour. This task presents a promising first step, laying the foundation for further research on the first impression's influence on behavioural variables. Hence, Task 2 continues on that topic by aiming to perform a more realistic approach, which is specified in the next section.

\section{TASK 2}

The second task planned to reach further verification of the first impression's impact on usage decisions. It examined the intention to stay on a website following both positive and negative first impressions with the aim to confirm the results from Task 1. While in the authors' opinion Task 1 can be criticized for its somewhat artificial character, this task came closer to a natural scenario. Participants landed directly on a website, skipping only the click on a search result (assuming that the first step includes the entry of a search term into a search engine). The main extension of Task 2 concerns the participants' expectations regarding the task. Whereas in Task 1 participants were aware of seeing the websites only for a brief span, we aimed to control for that consciousness by conveying a sense of seeing only one website. Ostensibly, we did not provide any time designation for this task. 
For Task 2, three appealing and three non-appealing screenshots of information websites were used (see Fig. 4).

\subsection{Procedure}

Participants were informed on the screen that the second part of the study was about to start. Following that, participants were asked to imagine themselves in the following scenario: 'you are having a discussion with your friends on the subject of why glue does not stick to the inside of the bottle. You are sure that you know the correct answer but your friends simply do not believe you.' Participants allocated to the goal condition were given the following add-on: 'in order to show your friends that you are right, you do an internet search for a website, which supports your argument.' All participants were told that they will see randomly one website from an existing sample of several websites on the subject of glue. Subsequent to the instruction, randomly either an appealing or a non-appealing website appeared on the screen for $2 \mathrm{~s}$ until a new window popped up, asking whether the participants wanted to stay on this website 'in order to explore it at their own pace' (action mode) / 'to answer the question' (goal mode) or whether they would prefer to see another website instead (goal and action mode). After they continued (i.e. stayed or left) a loading animation showed up for $3 \mathrm{~s}$. Subsequently, a loading error message was displayed saying that the page could not load and that the 'Continue'-button needs to be pressed to reload the page. Next, a new website appeared (regardless of whether participants indicated to stay or leave). Determined by the level of website aesthetics (appealing or non-appealing) participants were presented before, the opposite aesthetics level was presented, again for $2 \mathrm{~s}$. The following procedure was the same as for the first website including the stay-or-leave question, but the loading error message was replaced by an error message, stating that a system error occurred. Then, participants were redirected to a page where they were informed that the second part is completed and that they may start the third part when ready.

Note that the goal was to assess the intention to stay on a website for each participant for both appealing and nonappealing websites. The implementation of the error message was therefore an effort to prevent awareness about the research objective (first impression) within participants.

\subsection{Measures}

While seeing a website, a pop-up window appeared. Participants were asked: 'would you like to stay on this website or would you prefer to see another website instead?' The number of appealing and non-appealing websites participants indicated to stay on or to leave, respectively, was counted. Note that half of the participants randomly saw first one appealing and then one non-appealing website. The other half randomly saw the same but in the reverse order.

\subsection{Results}

For $\mathrm{H}_{3}$ we anticipated a difference between the intentions to stay on websites following either positive or negative first impressions. To test $H_{3}$, we used McNemar's test to examine differences in distribution between the intention to stay on or leave the website and between positive and negative first impression $(2 \times 2$ design $)$. As the proportions of the intention to leave or stay were equal between goal and action mode (Pearson's Chi-square test revealed no significant difference

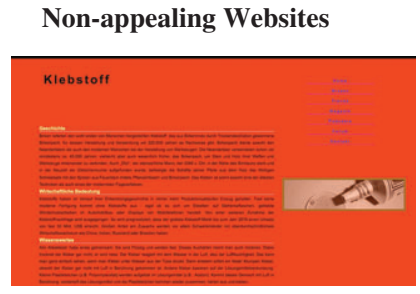

$M=2.14(0.86)$

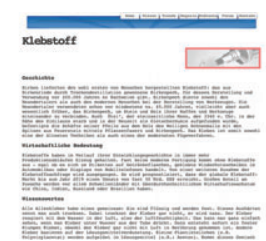

$M=2.83(1.16)$

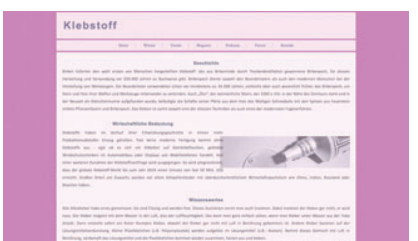

$M=2.88(1.29)$

Appealing Websites

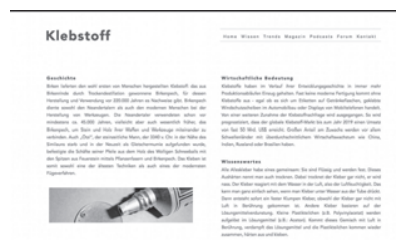

$M=4.84(0.99)$

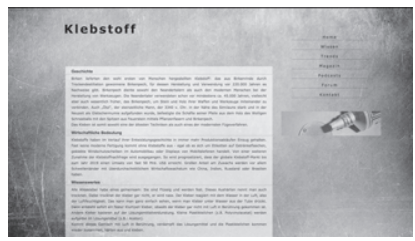

$M=4.78(1.41)$

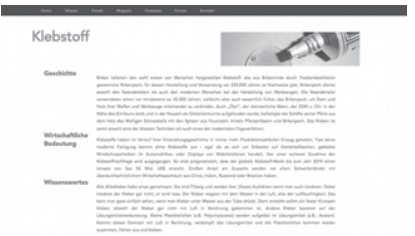

$M=4.57(1.11)$

FIGURE 4. Screenshots of Task 2, including the mean and standard deviation of VisAWI ratings (data of the prestudy) under each screenshot. 
in distribution $\left.\chi^{2}(1)=0.21, P=0.644\right)$, the analysis was conducted for the two usage modes separately.

Within goal mode 41 participants $(68.3 \%)$ intended to stay on the website when the website was appealing, whereas 19 participants (31.7\%) intended to leave the website despite its appealing design. When confronted with a non-appealing design exactly the same amount of participants (41 resp. $68.3 \%$ ) indicated to leave the website when confronted with a non-appealing design and $19(31.7 \%)$ indicated to stay, respectively. Precisely $50 \%$ of the participants behaved according to hypothesis $H_{3}$, meaning, they intended to stay on the website when coming upon an appealing design and to leave in case it was non-appealing. In the contrary, $13.3 \%$ intended to stay in the event of a non-appealing website and to leave when it was appealing. A McNemar's test (McNemar, 1947) with continuity correction (Edwards, 1948) was run to determine if there was a difference in the proportion of the intention to stay on appealing versus non-appealing designs. The difference was statistically significant, $\chi^{2}(1)=11.60, P=0.002$.

In action mode the intention to stay on appealing websites was manifested by 48 participants (80\%), whereas 12 participants $(20 \%)$ did not want to stay. 44 participants $(73.3 \%)$ indicated the intention to abandon non-appealing websites, yet 16 participants $(26.7 \%)$ remained on non-appealing versions. $61.7 \%$ of the participants behaved according the hypothesis $H_{3}$ (i.e. they intended to stay when the website was appealing and to leave when it was non-appealing). $8.3 \%$ intended to stay on a website with non-appealing design and to leave despite an appealing design. The McNemar's test shows that the difference in the proportion of the intention to stay on appealing versus non-appealing websites was statistically significant, $\chi^{2}(1)=22.88, P<0.001$. Figure 5 depicts both effects of website appeal in action and goal mode.

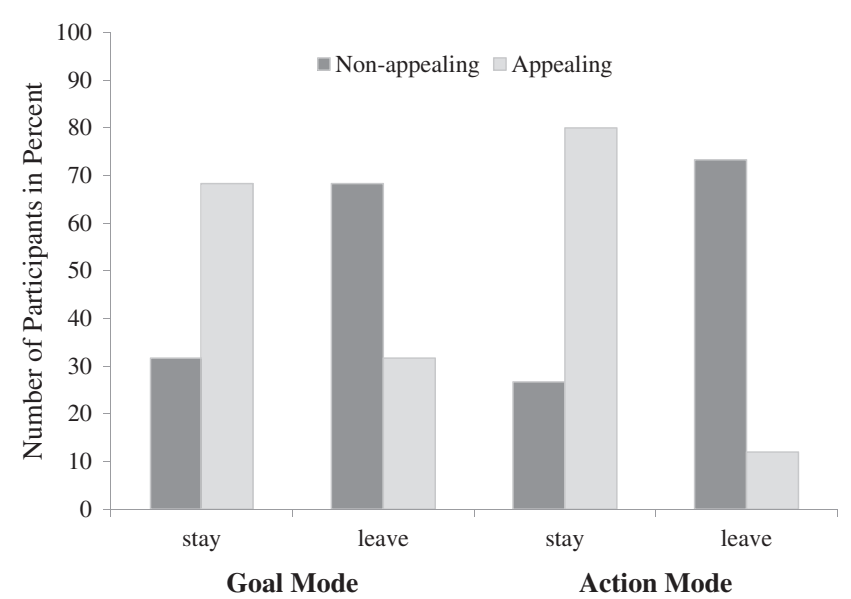

FIGURE 5. Number of participants (in percent) who indicated to stay or leave the website by visual appeal and usage mode (goal mode: left; action mode: right).

\subsection{Discussion}

The results of the second task are in line with $H_{3}$ and provide a more realistic insight on the first impression's significance in terms of behaviour it triggers compared to Task 1. In relation to the reported impact of first impressions on subsequent decisions (Task 1), these findings largely confirm that effect. Yet the subsequent behaviour was operationalized differently. In both usage modes, the major part of participants intended to remain on websites following a positive first impression. In contrast, an antecedent negative first impression caused mainly website abandonment.

As in Task 1, content and usability are believed to be barely accessible within $2 \mathrm{~s}$ of exposure (cf. Robins and Holmes, 2008). Thus, we suggest that the positive effect of a favorable first impression on the intention to remain on websites is again mainly due to a successful manipulation of the website's aesthetics.

The first two tasks show that individuals make fairly consistent decisions following both positive and negative first impressions. These findings shed light on the potential powerfulness of first impressions in regard to website usage behaviour, but yet we should not leap to conclusions as there is one major pitfall that constrains the meaningfulness of the results. In both tasks, the assessed behaviour (i.e. the willingness to view websites and the intention to stay on websites, respectively) came into being by forcing participants to act after a brief exposure. However, this shortcoming can be justified as short exposure times are standard in the context of measuring first impressions (Lindgaard et al., 2006; Tuch et al., 2012b). In Task 3, we will address whether when not forcing participants to call a decision, the first impression proves equally powerful.

\section{TASK 3}

The third part of this study aimed to explore how the first impression affects participants' website usage behaviour when acting self-paced. It focuses upon the dwell time and on different time intervals until leaving the first website, both in dependence of the first impression and usage mode. Participants either saw first randomly an appealing or non-appealing website. Consequently, website appeal was treated as a betweensubject factor. This task goes once again a step further in terms of relation to reality as it contains a search result page with links to different websites. But we omitted the usual brief descriptions of the contents (i.e. snippets) below the links, because recent research indicates that those snippets may influence users' behaviour (Clarke et al., 2007; Marcos et al., 2015).

\subsection{Procedure}

Participants were instructed that they were about to see a search result page containing six links labeled as Website 1 , Website 2, etcetera with different websites on the topic of 
microwaves' effect on vitamins behind the links. Participants in action mode were further told 'to explore these websites at their own pace.' The further instruction for goal mode was: 'to look for the answer whether microwaves destroy food's vitamins.' Additionally, all participants were informed that they would be redirected automatically after some time and, presumably, the time might not suffice to read through all websites. Once the participants continued, they could click on the search result links and when on a website, they could go back to the search results again to switch websites. To prevent sequence effects, the websites behind the links were randomized for every participant.

\subsection{Measures}

Dwell time was operationalized as the time participants spent on the first website until leaving it. The total time was restricted to $60 \mathrm{~s}$ as it was deemed to be sufficient time in order to quantify the first impression's effect on website usage. Time tracking started as soon as participants arrived on the search result page and ended when participants left the first visited website. We only looked at the first visited webpage, because it was the first positive or negative impression they were randomly exposed to. In addition, it was the most natural time frame, since participants only had $60 \mathrm{~s}$ to scan the website and would have, in a majority of cases, been interrupted on the second page.

\subsection{Stimuli}

Three appealing and three non-appealing screenshots of information websites were used. All website stimuli contained different contents on the same topic (see Fig. 6 for website screenshots). To control for content effects, the contents of the non-appealing websites were exchanged with the contents of the appealing websites after 60 of 120 participants took part in the experiment.

\subsection{Data preparation and statistical test selection}

Due to technical difficulties while data was tracked, four participants (3.3\%) were excluded from the analysis of this task. The final sample consisted of $N=116$, equally distributed among the two usage modes. Note that each participant randomly saw either an appealing or non-appealing website. In a first step, a two-way ANOVA with website aesthetics and usage mode was conducted, in order to assess the general effect of first impressions and usage mode on dwell time on the first visited website. Secondly, the life-table method was used in order to gain insights in greater detail on the time-dependent

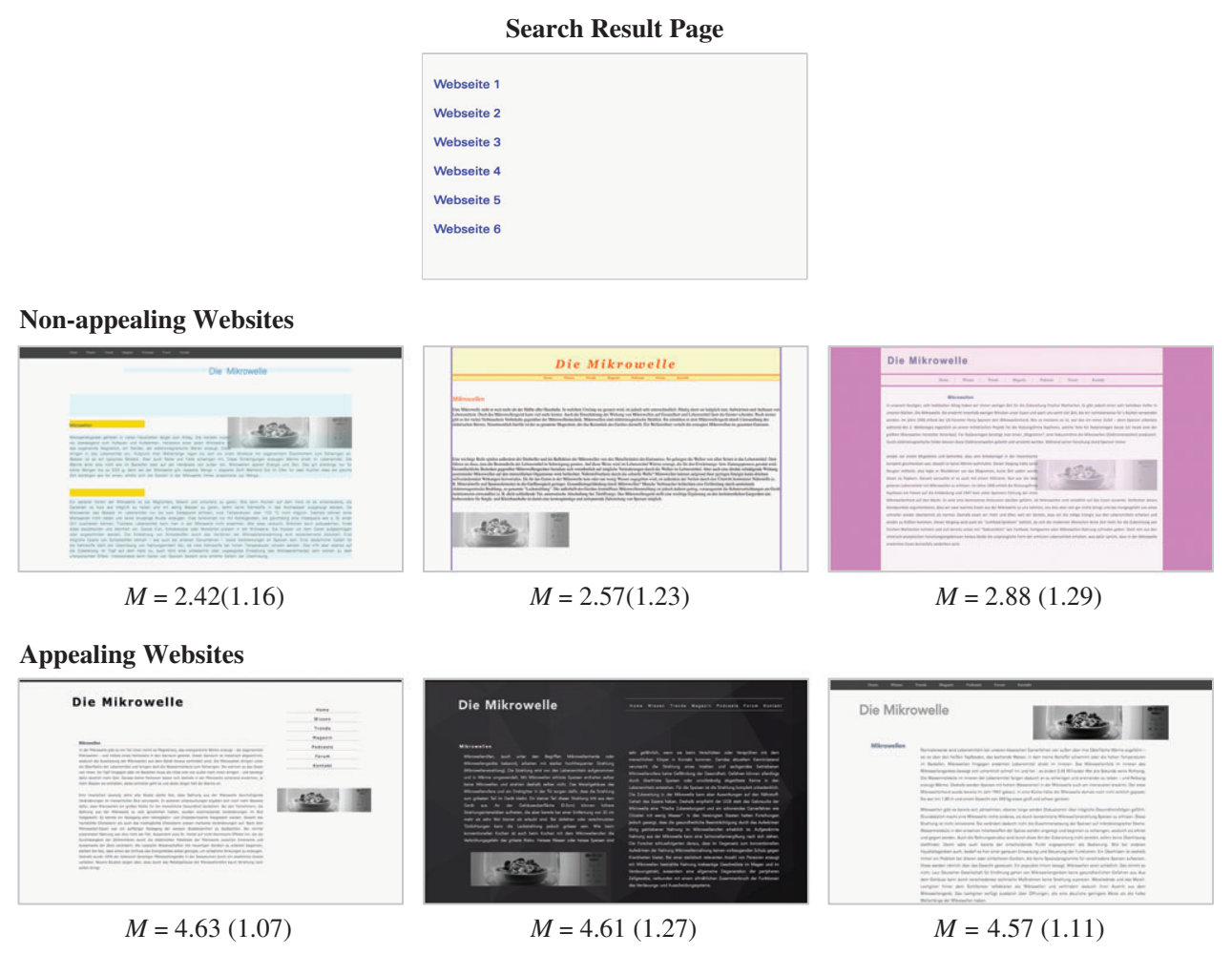

FIGURE 6. The first row shows the starting point (search result page). By clicking on a link each participants arrived randomly either on a non-appealing website (second row) or on an appealing website (third row). Under each screenshot the mean and standard deviation of VisAWI ratings (data of the prestudy) are displayed. 
course of the first impression's behavioural influence. Lifetables are part of the Survival analysis, which is a technique for observing temporal changes to an event using different time intervals. The procedure using the life-tables is classically applied within clinical or medical assessments, investigating the time to an event (e.g. onset of disease until death) (Luke and Homan, 1998). For analyzing the survival rate of websites, we simply replaced 'death' with 'website abandonment'.

\subsection{Results}

The data undergoing a two-way ANOVA did not violate the assumption of homogeneity of variances for each combination of the groups of website appeal and usage mode as assessed by Levene's test $(F(3114)=1.29, P=0.280)$.

There was no significant interaction for website aesthetics and usage mode on dwell time $F(1,112)=0.63, P=0.430$. The main effect of website aesthetics on difference in dwell time between positive first impressions (i.e. appealing websites) and negative first impressions (i.e. non-appealing websites) was also not statistically significant with $F(1,112)=$ $1.11, P=0.295$, indicating that negative first impression does not cause faster website leaving behaviour than positive first impression $\left(H_{4}\right)$. There was a statistically significant main effect of usage mode $F(1,112)=8.33, P<0.01$, partial $\eta^{2}=0.069$, which indicates that participants in action mode abandon websites more quickly but independently of website appeal, thereby rejecting $H_{5}$. The effect of usage mode is displayed in the bar chart of Fig. 7.

As the interaction was not significant, and an interaction contrast to confirm $H_{5}$ made no sense, we conducted pairwise post hoc contrasts with the Tukey method. These contrasts only indicate a significant difference in dwell time between goal mode and action mode, when appealing and non-

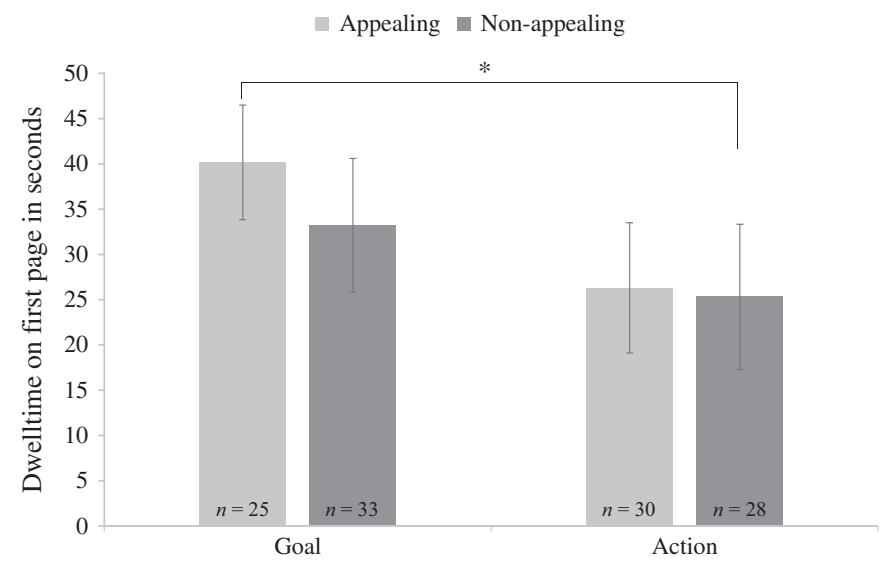

FIGURE 7. Dwell time (in seconds) on first visited page by usage mode and website appeal. Error bars represent $95 \%$ CI. $*$ is equal to $P<0.05$. appealing websites were compared $(P=0.043)$. The difference between the usage modes was no more significant when looking only at appealing websites $(P=0.060)$. All further comparisons were also not significant $(P>0.05)$ (see Fig. 7), thereby rejecting $H_{5}$.

\subsubsection{Survival analysis of websites}

This report provides a period life table, indicating the abandonment of the first visited website at a specific point in time. In our study, the term 'survival' denotes that the website is viewed (i.e. users are on the website). Reversely, website failure constitutes the point of leaving the first website (i.e. abandonment).

A large percentage $(42.6 \%)$ of participants left the first website within $20 \mathrm{~s}$ following a negative first impression. In contrast, subsequent to a positive first impression, websites were abandoned to a lesser extent for the same time frame (34.5\%) (see Fig. 8). However, the overall comparison of the survival rate was not significantly different after positive and negative first impressions, suggesting that website appeal had no impact on website abandonment $\left(\chi^{2}(1)=1.50, P=0.22\right)$, thereby rejecting $H_{4}$.

Regarding the usage mode, $53.4 \%$ of participants in action mode left the first page by the 20th second. In contrast, only $24.1 \%$ of participants in goal mode left in the same time interval (see Fig. 9). Overall, the survival rate between goal and action mode was significantly different with $\chi^{2}(1)=4.90$, $P<0.05$, complying with the effect of usage mode found in the previous ANOVA.

Finally, Fig. 10 depicts the difference between goal and action mode from the 5th until the 50th second. With respect to goal mode, participants tend to stay longer when the website was appealing than when it was not appealing. Whereas in action mode, there is only a difference within the first $20 \mathrm{~s}$. Although, the survival distributions of the four conditions were marginally not significant $\left(\chi^{2}(3)=6.9, P=0.076\right)$, thereby rejecting $H_{5}$.

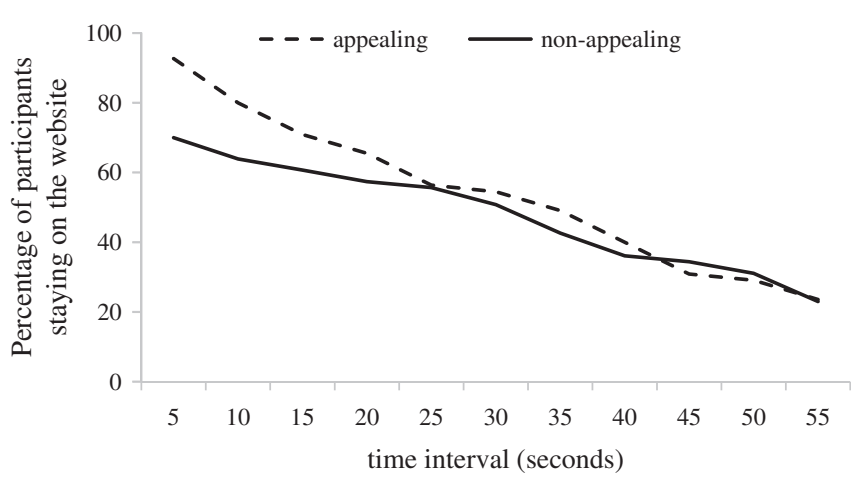

FIGURE 8. The lines indicate the percentage of participants remaining on the respective website at each time interval split by website appeal. 


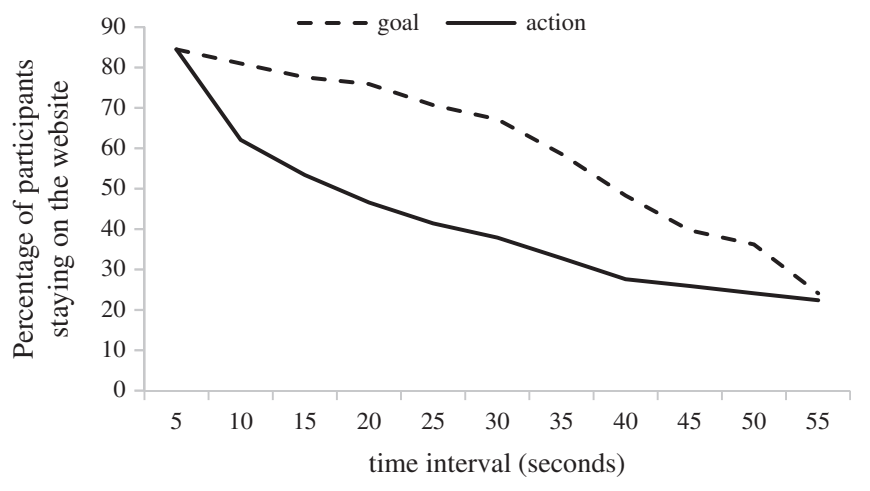

FIGURE 9. The lines indicate the percentage of participants remaining on the respective website at each time interval split by usage mode.

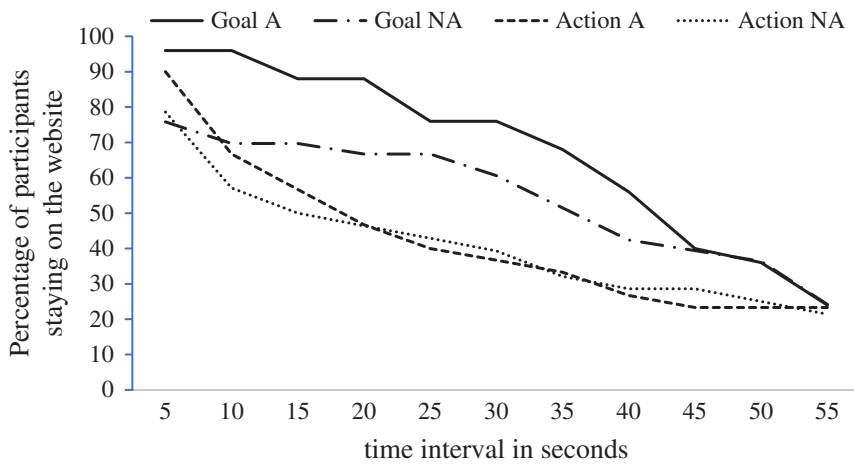

FIGURE 10. The lines indicate the percentage of participants remaining on the respective website at each time interval split by website appeal and usage mode (A stands for appealing website; NA for non-appealing website).

\subsection{Discussion}

In contrast to our expectations the usage mode proves to be of higher importance than the website appeal. Task 3 revealed that in action mode participants abandoned websites faster than those in goal mode. As can be seen in Fig. 10, the best survival rates were found for participants in goal mode looking at appealing websites.

Analysis of the first $10 \mathrm{~s}$ reveal that individuals in action mode abandoned a website more than twice as fast as participants in goal mode after experiencing a positive first impression (57.1\% versus $12 \%$ ). Following a negative first impression, there is a noticeable difference between goal (68.7\%) and action $(57.1 \%)$ mode as well. Although not statistically verifiable, our data indicates descriptive evidence with regard to the aesthetics' impact: within goal mode, the website abandonment rate is higher after negative first impressions (30.3\%) than after positive first impression (4\%) during the first $10 \mathrm{~s}$. The difference within action mode is somewhat smaller $(42.9 \%$ subsequent to negative first impressions versus $33.3 \%$ subsequent to positive first impressions) for the same time frame.
Analysis of the first $20 \mathrm{~s}$ indicate that participants in action mode leave an appealing website still considerably faster than participants in goal mode (53.3\% versus $12 \%$ ). For nonappealing websites the ratio is $53.6 \%$ (action) versus $33.3 \%$ (goal). Within goal mode, aesthetics still appears to have an impact on the website usage behaviour as $88 \%$ remained on appealing websites compared to $66.7 \%$ on non-appealing websites. However, no such pattern can be observed in action mode, suggesting no influence of website aesthetics.

The reason that eventually almost all participants, even in goal mode, abandoned the websites within $60 \mathrm{~s}$, is most likely down to the fact that the contents did not provide the exact answer to the posed question. This was done on purpose since we were interested in how long it would take until participants abandoned the website. In addition, this was done to counteract the probability that participants remained on the websites due to its content and not due to its level of aesthetics.

The third task differs from the previous two tasks on two basic aspects: Content und usability gain more relevance with more available time (see Thielsch et al., 2013). It is conceivable that content becomes more important since participants actually had the chance to look at it more thoroughly. Yet, we controlled a possible confounding effect by changing the content between all appealing and non-appealing websites for 50\% of the participants.

Concerning perceived usability, we tried to reduce a possible confounding effect by constraining the interaction to scrolling the webpages in all cases, which may have reduced the likelihood of affecting the decisions whether or not to use a page. Nevertheless, participants could have perceived the more aesthetic website as more user friendly (e.g. due to its improved colour contrast). As usability was not in the scope of our study, we have not assessed perceived usability and have no evidence whether visual appeal did affect the perception of usability. Future research could however account for perceived usability as a possible confounder.

\section{GENERAL DISCUSSION}

The notion of the first impression's influence on the subsequent behaviour in terms of website usage is prevalent in existing research literature (e.g. Lindgaard et al., 2011; Tuch et al., 2012b; van Schaik and Ling, 2009). Therefore, the study objective was to deliver empirical evidence of first impressions' post-incident impact on different website usage variables (i.e. willingness to view; intention to stay; time until leaving). In this study, the level of aesthetics was manipulated to trigger either positive or negative first impressions. It was demonstrated in a series of three tasks that individuals' decisions whether using a website or not, differ in dependence of usage mode and type of first impression they experienced. These findings provide a valuable insight on the first impression's potential. Whereas the first two tasks are indicative of the website aesthetics' significance, the results of Task 3 follow a different track. It was found that the action mode leads to earlier 
abandonment of the website than the goal mode and that in the goal mode a positive first impression tends to increase dwell time for the first $20 \mathrm{~s}$. Hence, website appeal may have a short-term impact on website visitors and usage mode seems to have a stronger and longer lasting impact on website usage.

\subsection{First impression's time frame and user behaviour}

Plenty of research demonstrated the rapidity of first impression formation (Lindgaard et al., 2006; Tractinsky et al., 2006; Tuch et al., 2012b), yet it was unclear whether it affects the subsequent behaviour in the same pace. Despite Lindgaard et al.'s (2006) concluding suggestion to investigate first impressions' consequences regarding its subsequent behaviour, many authors took it for granted that the first impression determines website success in terms of whether the website is used or not (Lindgaard et al., 2011; Tuch et al., 2012b; van Schaik and Ling, 2009). In the first two tasks of our study it became apparent that the first impression matters-positive first impressions evoked usage intentions in the context of information search on websites. However, normally users are not coerced to make decisions within $2 \mathrm{~s}$. Taking up this point, Task 3 shows that first impressions are not equally fast in determining the subsequent behaviour when acting self-paced, as neither positive nor negative first impressions did cause website abandonment at the outset (see Fig. 10).

According to Liu et al. (2010), users skim through websites after landing to weigh the benefits the page may provide. In case a website is approved, individuals search for the information needed. Based on their comprehensive calculations, the first $10 \mathrm{~s}$ are the most critical for websites in terms of being used or dismissed. According to our website survival analysis, the first $10 \mathrm{~s}$ proved to be decisive but only for users in action mode independent of the website's aesthetics. In goal mode the first $10 \mathrm{~s}$ were not that decisive, although it seems that aesthetics played a minor role in website abandonment. The reason of our differing findings may be due to the inclusion of usage mode and aesthetics compared to the nonexperimental approach of Liu et al. (2010).

This work's subject and findings prompt the question about the first impression's time frame, however, that clarification is beyond the scope of this study. Instead, the crucial $10 \mathrm{~s}$ line emphasized by Liu et al. (2010) appears a reasonable time frame to narrow down the first impression's behavioural effect. The high correlations in aesthetics ratings between $500 \mathrm{~ms}$ and $10 \mathrm{~s}$, shown by Tractinsky et al. (2006), serve as further support for this time limit.

\subsection{First impression in the usage context}

Originally the usage mode was included as an additional variable, as the perception of aesthetics has been shown (De Angeli et al., 2006) or discussed (Hassenzahl, 2003; Van
Schaik and Ling, 2011) to depend on the users' mindset. Interestingly, the study yields contradicting findings concerning the usage mode's influence. The results of Task 1 revealed a rather small interaction, indicating that the effect of aesthetics on willingness to view a website can depend on usage mode, whereas in Task 3 the usage mode was the only factor influencing participants' actual behaviour.

The reason for this difference may be sought in the slightly differing approach of the usage mode's manipulation. In Task 1 we asked participants to imagine a particular scenario (i.e. having a knee injury and being unsure whether a bandage or air better supports the injury's healing). Hence, participants may have had an implicit urge to seek for an answer to the scenario even without explicit instructions. This implies that participants in action mode would have had a goal as well and thus, no differences regarding usage mode were observed. In Task 3 the wording in the instruction was more general, thus allowing for the effect of usage mode to occur.

The short exposure time ( $2 \mathrm{~s}$ ) of Task 1 may be identified as a further contributory factor to the different findings in regard to the usage mode's effect. It is conceivable that the usage mode starts to affect usage behaviour only after some seconds. A reasoning for this effect may be derived from the model of aesthetic perception of art objects, provided by Leder et al. (2004). Current research in HCI uses this model as reference for time-sensitive processing of website aesthetics (Thielsch et al., 2013; Tuch et al., 2012b). Whereas the early stages of the model depict spontaneous and unconscious aesthetic processing of stimuli, higher cognitive aspects emerge increasingly during the temporal progress. The later stages include the formation of self-related-cognitive information that contains the association of the stimuli with the perceivers' situation and their interest in the perceived object. By drawing a parallel between usage mode, which represents a mental state of users (Hassenzahl, 2003), and the perceiver's situation and thus its cognitive state, our findings may give an explanation about the delayed onset of the usage mode within website usage.

Our descriptive observations (Fig. 10) are preliminary but not in line with previous research on the usage mode (Hassenzahl et al. 2002; Kauer et al., 2013; Van Schaik and Ling, 2009; Van Schaik and Link, 2011). Accordingly, individuals may not attach more value to aesthetics in action mode than in goal mode. Conversely, individuals with an explicit goal may rely on both hedonic (e.g. aesthetics) and pragmatic (i.e. usability) qualities. But because we deem usability as a matter of negligible importance on the applied websites, hedonic attributes may have been the chief reference point for participants. In the light of the longer dwell time on websites within goal mode compared to action mode, it appears that participants endure in the presence of an explicit goal more patiently as in action mode, where participants switched the websites quickly in a highly explorative way (see Figs 9 and 10). This estimate goes along with Hassenzahl's (2003) 
descriptions: goal-oriented individuals approach tasks seriously and strive for effectiveness and efficiency. Hence, their attitude would not tolerate to get off course merely due to a lack of aesthetics. Our data is in line with this perspective, despite a slight preference for appealing website. However, our results do not support the following assumption of Hassenzahl (2003), that in absence of any goals, individuals act spontaneously and need stimulation as for instance in form of aesthetics. According to Fig. 10, in goal mode positive first impressions appear to lead to greater attentional focus and perseverance when scanning a website for potential benefits corresponding to their explicit goal. Subsequent to negative first impressions, our participants ceased trying to continue the search for information more quickly. In action mode, however, the type of first impression seemed not to influence users' perseverance, instead participants often switched between webpages, because they were in an exploratory mode, independent of visual appeal. Thus, to the preliminary findings that aesthetics has a positive effect on search perseverance (Nakarada-Kordic and Lobb, 2005) we add that this is only true if individuals are in goal mode.

\subsection{Practical implications for design}

The contribution of our findings may be less significant for interaction design practice than for research. Nonetheless, as a practical implication within the context of information search we can state that designers should always strive after improving the visual appeal. A good first impression has a positive effect on user's intention to stay on a website, willingness to revisit it and actual dwell time. However, instead of spending all resources in design-related considerations, we suggest that it is crucial to take the usage context into account - ideally by strengthen the users' specific goals or even by bringing them about as part of the user experience journey.

To pretest our experimental stimuli, we manipulated and validated colour, structure and font of the website. This significantly affected willingness to view and intention to stay on a website, indicating that for a first positive impression, visually appealing colour, structure and font are relevant. For designers, there may be even more interesting combinations of visually appealing design options to consider. However, we suggest considering the context of use as well, since our results indicate that usage mode may even play a more crucial role for actual usage behaviour, at least in the long run. If a website has users who are more likely to look for specific information (i.e. users in goal mode), it is expectable that they are sensitive to the appeal of the website's design (see Fig. 10). For instance, it is advisable taking into account that visually less appealing designs may, especially in goal mode, negatively affect users' mental effort (Hassenzahl and Ullrich, 2007) and their perception of usability (van Schaik and Ling,
2009), increasing the odds of leaving the website. Furthermore, for users who merely explore the website (i.e. users in action mode), website providers should find ways to nudge their visitors towards specific goals. A possible design solution could be to formulate keywords or questions that users of the respective website could have to guide themselves through the informative website content. These cues could then be presented in different ways such as displaying one of these cues prominently and next to the main text, or a chatbot that interacts with the user helping to find answers.

\subsection{Limitations and further research}

For the interpretation of the results some limitations need to be considered. Some participants came across websites with the same design characteristics twice over the course of the three experiments, giving rise to the mere exposure effect (Zajonc, 1968). This implies that in Tasks 2 and 3 participants' usage decisions may have been intensified because of repeated viewing. However, all tasks used different topics, differed in text length and images used on the websites. Future research on that subject would profit by applying a larger range of stimuli.

In consideration of the manipulation check almost all participants $(n=59)$ of the goal mode condition indicated the correct mindset ('specific task'). In regard to action mode however, 41 participants indicated having a specific task too, while only 19 participants in action mode indicated to be task-free. We can think of three reasons for this outcome: (i) it is imaginable that due to the experimental setting participants felt goal-driven from the start of the experiment and even the invitation to explore the websites according to their own liking could not change that mindset; (ii) information websites, as a specific website genre, involve a goal per se since one would normally not expect users to explore such pages without a specific goal (i.e. find an answer on a topic); (iii) the manipulation failed. Nonetheless, we adopted this approach from a study where a manipulation of goal and action mode worked (van Schaik and Ling, 2009) and since the manipulation of mode of use yielded a decent effect for Task 3, showing that mode of use affects participants only after some time, the null-effect concerning Task 1 may not be necessarily due to failed manipulation. As this issue may have occurred due to the nature of the task (i.e. search on information website), future research could explore other ways to manipulate usage mode and investigate it on other website contexts where first impression could be of high importance (e.g. e-commerce).

Websites with a strongly non-appealing character as we used in our study may be encountered rarely on the web. Although our appealing websites have some room for improvement, the stimuli material was different regarding their aesthetics. For 
future research, it could be useful to manipulate a greater spectrum of aesthetics, in order to determine the required aesthetics level with regard to convince users to remain on websites. Moreover, aesthetics has been established as multidimensional construct (Lavie and Tractinsky, 2004; Moshagen and Thielsch, 2010), thus, it might be that the manipulation of different dimensions of aesthetics compensate or even reinforce the effects found in this study.

\section{CONCLUSION}

Many researchers stressed the influence of first impressions on the subsequent behaviour without substance-it turned out that their assumption may be wrong. The impact of first impressions on individuals' usage behaviour was only evident when participants were coerced into a decision after a $2 \mathrm{~s}$ exposure. No such effect was observed when participants explored the websites self-paced. Instead, websites are more likely to be actually looked at in dependence of the usage mode. Participants persevere on websites when they try to reach an explicit goal rather than when they explore, which becomes apparent already after $10 \mathrm{~s}$. In sum, willingness to view and stay on a website was higher for positive first impressions, in goal mode participants tend to persevere the longest on more appealing websites. This however may only count for informational websites implying more explicit goals, such as looking for a recipe to bake a delicious chocolate cake. Based on that future research should consider to look at websites that are less informational.

\section{ACKNOWLEDGEMENTS}

We sincerely thank Alexandre Tuch for his valuable inputs and support at the beginning of this research project. Furthermore, we would like to express our gratitude to Silvia Heinz, Sharon Steinemann, and the reviewers for their very helpful and valuable feedback to this paper.

\section{REFERENCES}

Bölte, J., Hösker, T.M., Hirschfeld, G. and Thielsch, M.T. (2017) Electrophysiological correlates of aaesthetic processing of webpages: a comparison of experts and laypersons. Peer. J., 5, e3440.

Clarke, C.L., Agichtein, E., Dumais, S. and White, R.W. (2007). The influence of caption features on clickthrough patterns in web search. In Proceedings of the 30th annual international ACM SIGIR conference on Research and Development in Information Retrieval (pp. 135-142).

De Angeli, A., Sutcliffe, A. and Hartmann, J. (2006). Interaction, usability and aaesthetics: what influences users' preferences? In Proceedings of the 6th conference on Designing Interactive Systems (pp. 271-280).
Ding, Y., Guo, F., Hu, M. and Cao, Y. (2017) Using event related potentials to investigate visual aaesthetic perception of product appearance. Hum. Factors Ergon. Manuf. Serv. Ind., 27, 223-232.

Douneva, M., Jaron, R. and Thielsch, M.T. (2016) Effects of different website designs on first impressions, aaesthetic judgements and memory performance after short presentation. Interact. Comput., 28, 552-567.

Flacke, L., Jaron, R. and Thielsch, M.T. (2015). Websitebewertung: Der spontane Ersteindruck. In Mensch and Computer (pp. 399-402).

Geissler, G.L., Zinkhan, G.M. and Watson, R.T. (2006) The influence of home page complexity on consumer attention, attitudes, and purchase intent. J Adv, 35, 69-80.

Girden, E.R. (1992) ANOVA: Repeated Measures. Sage, Newbury Park, CA.

Hall, R.H. and Hanna, P. (2004) The impact of web page textbackground colour combinations on readability, retention, aaesthetics and behavioural intention. Behav. Inf. Technol., 23, 183-195.

Harrison, L., Reinecke, K. and Chang, R. (2015). Infographic aaesthetics: designing for the first impression. In Proceedings of the 33rd Annual ACM Conference on Human Factors in Computing Systems (pp. 1187-1190).

Hartmann, J., Sutcliffe, A. and Angeli, A.D. (2008) Towards a theory of user judgment of aaesthetics and user interface quality. ACM Trans. Comput. Hum. Int. (TOCHI), 15, 15.

Hassenzahl, M. (2003) The Thing and I: Understanding the Relationship Between User and Product. In Blythe, M.A., Overbeeke, K., Monk, A.F. and Wright, P.C. (eds), Funology: From Usability to Enjoyment, pp. 31-42. Kluwer Academic Publishers, Dordrecht, NL.

Hassenzahl, M., Kekez, R. and Burmester, M. (2002). The importance of a software's pragmatic quality depends on usage modes. In Proceedings of the 6th International Conference on Work With Display Units (WWDU 2002) (pp. 275-276).

Hassenzahl, M. and Ullrich, D. (2007) To do or not to do: differences in user experience and retrospective judgments depending on the presence or absence of instrumental goals. Interact. Comput., 19, 429-437.

Jiang, Z., Wang, W., Tan, B.C. and Yu, J. (2016) The determinants and impacts of aaesthetics in users' first interaction with websites. J. Manage. Inf. Syst., 33, 229-259.

Kauer, M., Theuerling, H. and Bruder, R. (2013) The importance of identification for the acceptance of consumer electronics on the example of the Wii. Behav. Inf. Technol., 32, 344-358.

Kim, H. and Fesenmaier, D.R. (2008) Persuasive design of destination web sites: an analysis of first impression. J. Travel Res., 47, 3-13.

Lavie, T. and Tractinsky, N. (2004) Assessing dimensions of perceived visual aaesthetics of web sites. Int. J. Hum. Comput. Stud., 60, 269-298.

Leder, H., Belke, B., Oeberst, A. and Augustin, D. (2004) A model of aaesthetic appreciation and aaesthetic judgments. Br. J. Psychol., 95, 489-508. 
Lindgaard, G., Dudek, C., Sen, D., Sumegi, L. and Noonan, P. (2011) An exploration of relations between visual appeal, trustworthiness and perceived usability ofhomepages. ACM Trans. Comput. Hum. Int. (TOCHI), 18, 1.

Lindgaard, G., Fernandes, G., Dudek, C. and Brown, J. (2006) Attention web designers: you have 50 milliseconds to make a good first impression! Behav. Inf. Technol., 25, 115-126.

Liu, C., White, R.W. and Dumais, S. (2010). Understanding web browsing behaviours through weibull analysis of dwell time. In Proceedings of the 33rd international ACM SIGIR Conference on Research and Development in Information Retrieval (pp. 379-386).

Luke, D.A. and Homan, S.M. (1998) Time and change: Using survival analysis in clinical assessment and treatment evaluation. Psychol. Assess., 10, 360-378.

Marcos, M.-C., Gavin, F. and Arapakis, I. (2015). Effect of snippets on user experience in web search. In Proceedings of the XVI International Conference on Human Computer Interaction ( $\mathrm{p}$. 47).

McNemar, Q. (1947) Note on the sampling error of the difference between correlated proportions or percentages. Psychometrika., $12,153-157$.

Michailidou, E., Harper, S. and Bechhofer, S. (2008). Visual complexity and aaesthetic perception of web pages. In Proceedings of the 26th Annual ACM International Conference on Design of Communication (pp. 215-224).

Miller, C. (2011) Aaesthetics and e-assessment: the interplay of emotional design and learner performance. Distance Educ., 32, 307-337.

Moshagen, M. and Thielsch, M.T. (2010) Facets of visual aaesthetics. Int. J. Hum. Comput. Stud., 68, 689-709.

Moshagen, M. and Thielsch, M. (2013) A short version of the visual aaesthetics of websites inventory. Behav. Inf. Technol., 32, 1305-1311.

Nakarada-Kordic, I. and Lobb, B. (2005). Effect of perceived attractiveness of web interface design on visual search of web sites. In Proceedings of the 6th ACM SIGCHI New Zealand chapter's International Conference on Computer-Human Interaction: Making CHI natural (pp. 25-27).

Nickerson, R.S. (1998) Confirmation bias: a ubiquitous phenomenon in many guises. Rev Gen. Psychol., 2, 175-220.

Olivola, C.Y. and Todorov, A. (2010) Elected in 100 milliseconds: appearance-based trait inferences and voting. J. Nonverbal Behav., 34, 83-110.

Parboteeah, D.V., Valacich, J.S. and Wells, J.D. (2009) The influence of website characteristics on a consumer's urge to buy impulsively. Inf. Syst. Res., 20, 60-78.

Reinecke, K., Yeh, T., Miratrix, L., Mardiko, R., Zhao, Y., Liu, J. and Gajos, K.Z. (2013). Predicting users' first impressions of website aaesthetics with a quantification of perceived visual complexity and colorfulness. In Proceedings of the SIGCHI
Conference on Human Factors in Computing Systems (pp. 2049-2058).

Robins, D. and Holmes, J. (2008) Aaesthetics and credibility in web site design. Inf. Process. Manag., 44, 386-399.

Sillence, E., Briggs, P., Harris, P.R. and Fishwick, L. (2007) How do patients evaluate and make use of online health information? Soc. Sci. Med., 64, 1853-1862.

Sonderegger, A. and Sauer, J. (2010) The influence of design aaesthetics in usability testing: effects on user performance and perceived usability. Appl. Ergon., 41, 403-410.

Sonderegger, A., Zbinden, G., Uebelbacher, A. and Sauer, J. (2012) The influence of product aaesthetics and usability over the course of time: a longitudinal field experiment. Ergonomics., 55, 713-730.

Thielsch, M.T., Blotenberg, I. and Jaron, R. (2013) User evaluation of websites: from first impression to recommendation. Interact. Comput., 26, 89-102.

Thielsch, M.T. and Hirschfeld, G. (2010) High and low spatial frequencies in website evaluations. Ergonomics., 53, 972-978.

Thielsch, M.T. and Hirschfeld, G. (2012) Spatial frequencies in aaesthetic website evaluations-explaining how ultra-rapid evaluations are formed. Ergonomics., 55, 731-742.

Tractinsky, N., Cokhavi, A., Kirschenbaum, M. and Sharfi, T. (2006) Evaluating the consistency of immediate aaesthetic perceptions of web pages. Int. J. Hum. Comput. Stud., 64, 1071-1083.

Tractinsky, N., Katz, A.S. and Ikar, D. (2000) What is beautiful is usable. Interact. Comput., 13, 127-145.

Tuch, A.N., Presslaber, E.E., Stöcklin, M., Opwis, K. and BargasAvila, J.A. (2012b) The role of visual complexity and prototypicality regarding first impression of websites: working towards understanding aaesthetic judgments. Int. J. Hum. Comput. Stud., 70, 794-811.

Tuch, A.N., Roth, S.P., Hornbaek, K., Opwis, K. and Bargas-Avila, J.A. (2012a) Is beautiful really usable? Toward understanding the relation between usability, aaesthetics, and affect in HCI. Comput. Human. Behav., 28, 1596-1607.

van Schaik, P., Hassenzahl, M. and Ling, J. (2012) User-experience from an inference perspective. ACM Trans. Comput. Hum. Int., $19,11$.

van Schaik, P. and Ling, J. (2009) The role of context in perceptions of the aaesthetics of web pages over time. Int. J. Hum. Comput. Stud., 67, 79-89.

Van Schaik, P. and Ling, J. (2011) An integrated model of interaction experience for information retrieval in a Web-based encyclopaedia. Interact. Comput., 23, 18-32.

Wellman, B. and Haythornthwaite, C. (2002) The Internet in everyday life. Blackwell Publishing, Malden, MA.

Zajonc, R.B. (1968) Attitudinal effects of mere exposure. J. Pers. Soc. Psychol., 9, 1-27.

Zajonc, R.B. (1980) Feeling and thinking: preferences need no inferences. Am. Psychol., 35, 151-175. 


\section{APPENDIX}

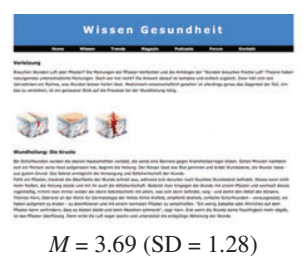

Figure Appendix. Screenshot of the website shown at the end of Task 1, including the mean and standard deviation of VisAWI ratings (data of the prestudy). Note that this website was not part of the measuring process for willingness to view. 